\title{
RAZONAMIENTO JUSTIFICATORIO JUDICIAL
}

Rodolfo Luis Vigo

Universidad Nacional del Litoral, Santa Fe (Argentina)

\section{De la visión legalista-dogmática a la judicialista-crítica. La importancia iusfilosófica de lo metodológico}

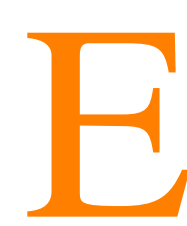

1 paradigma dogmático-legalista se constituyó en Europa continental en el siglo XIX básicamente a instancias de la escuela exegética, la escuela histórica y el primer Ihering, y entre sus diferentes postulados característicos destaquemos, a los fines del presente trabajo, los siguientes: 1. la sinonimia medular entre derecho y ley, remitiendo la Constitución al mundo no jurídico de lo político; 2. la tajante separación entre creación y aplicación del derecho, aquélla librada a la voluntad perfecta del legislador, y ésta confiada a una razón judicial aséptica, que mediante un elemental mecanismo de subsunción repetía sin dificultades la ley para el caso; y 3. el valor jurídico decisivo y central del modelo es la «seguridad jurídica», en cuanto saber a qué atenerse jurídicamente o contar con la respuesta previsible y anticipada para cada problema jurídico. Para ese paradigma no había espacio ni necesidad de razonamiento justificatorio, pues la decisión creadora del legislativo se justificaba en sí misma y era incontrolable, y luego venía el irrelevante silogismo formal judicial de rigurosidad teórica. De ahí la rudimentaria teoría interpretativa circunscripta a «reconstruir con fidelidad la voluntad del legislador», y la igualmente simple y rígida teoría de la fuente del derecho, centrada en la norma jurídica general, y más específicamente en la creada por el poder legislativo. Consecuentemente, aparecían las resistencias para confeccionar un listado de las fuentes del derecho complementarias de la ley, y así, por ejemplo, se llegaba dificultosamente a reconocer tal carácter a la costumbre, sólo en la medida que aclaraba la ley o suplía su silencio, pero nunca en oposición a la misma, y por el lado de la jurisprudencia, sólo para el supuesto que fuera reiterada y proveniente del tribunal de la máxima jerarquía.

Aquella «matriz disciplinar» continental sufrirá -según advierte simbólicamente Perelman'- un profundo agrietamiento en Nuremberg, al sacar a

\footnotetext{
${ }^{1}$ Perelman, C., La lógica jurídica y la nueva retórica, Ed. Civitas, Madrid. 1988, pág. 103.
} 
la luz sus insuficiencias y debilidades, y en las décadas siguientes padecerá un amplísimo y variado abanico de críticas que terminaran de socavar sus cimientos, de reducir el número de sus adherentes teóricos y de poner de relieve su distanciamiento cada vez más pronunciado con la realidad y la operatividad del derecho. Algunas de las derrotas más directas e importantes que experimentó aquel paradigma tienen que ver con el reconocimiento de verdadera fuente del derecho a los «principios generales del derecho», con la institucionalización del control constitucional, con la admisión que la sentencia judicial no se limitaba a «aplicar» la norma legal, con la presencia exigente y axiológicamente expansiva de los derechos humanos, y con el debilitamiento de las pretensiones cientificistas generales en favor de proporcionar respuestas jurídicas a la medida de los casos. Más allá del mundo estrictamente jurídico, la sociedad democrática y pluralista ya no estará dispuesta a legitimar -como observa Atienza ${ }^{2}$ por la remisión a la autoridad o por meras explicaciones estructurales o formales, sino pretende que la autoridad -a cuyo servicio está- tenga razones cuando toma una decisión, las haga conocer y las someta a la crítica ciudadana.

Los dos escenarios que más nos interesa subrayar son, por un lado, el de esa sociedad desconfiada de la autoridad y muy atenta y crítica con el modo en que la ejerce y, por el otro, haber recuperado el «sentido del derecho», que es el de resolver problemas jurídicos concretos en favor de las personas individuales o en cuanto miembros de sociedades. Insistiendo en este ángulo jurídico, resulta claramente arbitrario que por interés científico o por disponerlo un sector económico social se preste atención sólo a las normas jurídicas generales y se las constituya en fines en sí mismas y en el objeto exclusivo y excluyente del derecho y sus operadores. De lo que se trata, entonces, es de advertir que el derecho es una obra colectiva -parafraseando a Villey- que comienza a «determinar el constituyente con la mayor generalidad, pero que culmina el juez cuando, desde todo el derecho otorga una respuesta jurídica al problema que le llevaron los mismos que lo han constituido en autoridad.

El gran escenario jurídico olvidado por la teoría decimonónica ha sido el judicial $\mathrm{y}$, en consecuencia, la primera tarea para poder elaborar una teoría jurídica realista, integral y satisfactoria, es no sólo recuperar aquel sector del derecho, sino advertir que es el momento final y privilegiado para reconstruir un nuevo paradigma ${ }^{\mathrm{a}}$. El modelo iuspositivista decimo-

${ }^{2}$ Cfr. Atienza, M. Las razones del derecho. Ed. Centro de Estudios Constitucionales, Madrid, 1991, pág. 25.

${ }^{\text {a }}$ La explicación última de la existencia del juez se incardina con la presencia forzosa e inevitable de problemas jurídicos en la sociedad humana; por eso leemos en la «Ética a Nicó- 
nónico, a puro voluntarismo y reclamo de seguridad jurídica, nos sacó de escena al juez y, entonces, de ese concepto mínimo del derecho que habla Wroblewski ${ }^{3}$ sólo nos quedamos con las normas generales y se nos privó de las normas individuales. El derecho, más que un trabajo de equipo -como reclama Aarnio ${ }^{4}$ - se dispuso que sea sólo obra de legisladores y no de jueces. Estos postulados característicos de la metodología legalista-dogmática, establecidos legislativamente y consagrados académicamente por la ciencia jurídica respectiva, se sustentan y expresan una cierta filosofía absorbida y debilitada por la ciencia física-natural, lo que constituye la clave última del modelo ${ }^{5}$. El camino gnoseológico permitido por el paradigma científico imperante en el siglo anterior tiene a la ley jurídica como el equivalente perfecto de la ley científica ${ }^{6}$, y la seguridad o certeza jurídica reclamada desde el poder por la burguesía triunfante, no toleraba respuestas jurídicas a la medida de los casos. En definitiva, hay que volver a prestar atención privilegiada al espacio metodológico-jurídico, advirtiendo que es un verdadero «banco de pruebas» de cualquier filosofía jurídica ${ }^{\mathrm{b}}$. Parafraseando con libertad a Larenz ${ }^{7}$, podemos sintetizar lo que queremos expresar con el siguiente apotegma: «dime qué metodología jurídica sustentas y te diré qué filosofía jurídica sustentas o estás dispuesto a sustentar».

Es imprescindible que los iusfilósofos no perdamos de vista o, mejor aún, miremos con mucha y permanente atención el modo en que opera o pretendemos que opere el derecho, o sea, a la teoría de la interpretación jurídica comprensiva de la teoría de las fuentes del derecho, pero que además

maco»: «cuando están en desacuerdo los hombres recurren al juez, pues ir al juez es ir a la justicia, y el juez es la justicia animada (Aristóteles, «Ética a Nicómaco», 1132. a.)

${ }^{3}$ Wroblewski, J., «Sentido y hecho en el derecho», Universidad del País Vasco, San Sebastián, 1989, pág. 18.

${ }^{4}$ Aarnio, A., «Lo racional como razonable», Ed. Centro de Estudios Constitucionales, Madrid, 1991, pág. 33.

${ }^{5}$ Cfr. Massini, C., «La desintegración del pensar jurídico en la Edad Moderna», Abeledo Perrot, Bs. As., 1980.

${ }^{6}$ Balaguer Callejón, F., «Fuentes del derecho», Ed. Tecnos, Madrid, 1991, pág. 20.

${ }^{\mathrm{b}}$ Fue muy caro el precio que pagó la filosofía del derecho por culpa de los «filosofismos» que intentaron filosofías jurídicas a la medida de sus «sistemas filosóficos» aunque despreocupados por el derecho concreto; con acierto dice Kaufmann que «las dos preguntas fundamentales de la filosofía del derecho son: qué es el derecho correcto y cómo conocemos o llevamos a la práctica el derecho correcto» (Kaufmann, A. - Hassemer, W., «El pensamiento jurídico contemporáneo», Ed. Debate, Madrid, 1992, pág. 49.

${ }^{7}$ Larenz, K.: «Mostrar el desenvolvimiento progresivo de la Metodología jurídica, normalmente en consonancia con la evolución del pensamiento jurídico filosófico y éste a su vez en clara dependencia con los principios corrientes del pensamiento filosófico» («Metodología de la Ciencia del Derecho», Ariel, Barcelona, 1994, pág. 3). 
significa la dimensión dinámica del ordenamento jurídico ${ }^{8}$. Desde esta perspectiva se puede coincidir con Dworkin cuando pretende que la filosofía del derecho no sea un saber más sino que sea el «nervio de la reflexión sobre el derecho»?.

Por supuesto que, junto a la más cualificada doctrina actual -desde Finnis hasta Aarnio, pasando por Alexy o Dworkin-, por supuesto y dejando de lado matices, pensamos que toda teoría jurídica es inescindiblemente normativista y prescriptivista, lo cual supone renunciar por imposible e inconveniente a pretensiones desvinculatorias de lo descriptivo respecto a lo prescriptivo. Es que en aquella preocupación por comprender la filosofía jurídica en la metodología jurídica supone también reconocer y reclamar la unidad del saber práctico y, dentro de éste, del saber jurídico, más allá de sus niveles o particularidades de enfoque, y en esto también buena parte de la doctrina contemporánea coinciden: desde Cotta a MacCormick, pasando por Nino u Ollero.

Volviendo al escenario perdido, ya hace algunas décadas que desde lo político Lowenstein constataba «uno de los fenómenos más característicos de la evolución del Estado democrático constitucional es el ascenso del poder judicial a la categoría de auténtico detentador del poder del Estado» ${ }^{10}$. En un terreno más jurídico, Esser, luego de confesar que observaba claramente «la crisis de nuestra teoría de las fuentes del derecho», agregaba que «el centro de gravedad va desplazándose lentamente desde el sistema codificado a una casuística judicial orientada según principios» ${ }^{11}$, y desde Italia Mauro Cappeletti, sin perjuicio de reconocer que la interpretación judicial ha seguido siendo creadora, destaca que «un dato di falto che la maggiore accentuazione della creatività della funzione giurisdizionale a un fenomeno tipico del nostro secolo» ${ }^{12}$. Seguramente coincidimos con Larenz cuando escribe que «en la teoría ha sido hasta ahora sorprendentemente descuidada la interpretación de soluciones judiciales, a diferencia de la interpretación de las leyes y preceptos jurídicos» ${ }^{13}$, o con Asis Roig ${ }^{14}$, cuando describe la distancia que se verifica entre la teoría de las fuentes del derecho dominan-

${ }^{8}$ Cfr. Aarnio, A., ob. cit., pág. 141. Robert Alexy habla de los tres niveles del sistema jurídico: reglas, principios y teoría de la argumentación jurídica «Derecho y Razón Práctica», Fontamara, México, 1993, pág. 19.

${ }^{9}$ Dworkin, R., «La Filosofía del Derecho», Fondo de Cultura Económica, México, 1980, pág. 8.

${ }^{10}$ Loewenstein, K., «Teoría de la Constitución», Ariel, Barcelona, 1971.

${ }^{11}$ Esser, J., «Principio y norma en la elaboración jurisprudencial del Derecho Privado», Bosch, Barcelona, 1961, págs. 11 y 31.

${ }^{12}$ Cappeletti, M., «Giudici legislatori?», Giuffrè, Milano, 1984, pág. 19.

${ }^{13}$ Larenz, K., ob. cit., pág. 355. 
te en el mundo académico y la práctica jurídica tribunalicia, o con Viehweg, cuando concluye que el problema central de la ciencia jurídica es «qué es lo justo en cada caso» ${ }^{15}$, o con Warnock cuando precisa que «la aplicabilidad de una regla a un caso particular, por mejor que sea esa regla, no es, en general, una razón concluyente para actuar en esa situación como la regla lo exige» ${ }^{16}$. Pero estas coincidencias no son suficientes ni nos liberan de la responsabilidad de insistir en el cambio del paradigma y de lograr una teoría atractiva iusfilosóficamente sólida, capaz de ser internalizada por los juristas prácticos y el resto del mundo académico jurídico. Hay mucha inercia teórica aún donde más viva y plenamente está el derecho, que es en los tribunales, y por supuesto que aquélla también abunda entre los especialistas de las diferentes «ramas» del derecho vigente, y en una buena medida es tarea de la filosofía jurídica el romperla y promover el atractivo por preguntas y respuestas más consistentes y realistas.

Aún desde presupuestos distintos, compartimos la conclusión de Nino, cuando luego de descartar distintos modelos metodológicos de ciencia jurídica (el puro de Kelsen, el empírico de Ross y el «sistematizador» de Alchourron y Bulygin) reclama una ciencia o teoría jurídica «normativa», que preserve y rescate «lo que los juristas efectivamente hacen y las funciones que satisfacen, proporcionando un esquema de argumentación jurídica que se ajuste a esa actividad», capaz de «proporcionar pautas de lege ferenda que permitan justificar y enjuiciar regulaciones jurídicas positivas y orientar su eventual modificación», y de «proponer formas para completarlo y reconstruirlo, de modo do, permitir derivar soluciones axiológicamente satisfactorias», teniendo en cuenta que «el derecho positivo no provee razones suficientes para justificar una decisión aun cuando el orden en cuestión contenga una solución clara para el caso que debe decidirse. Si el concepto de derecho se define, como los positivistas proponen, sobre la base de propiedades fácticas y sin recurrir a características valorativas o normativas, las proposiciones que dicen que un cierto derecho positivo establece una obligación, un derecho, una sanción, etc., para un determinado caso, son reducibles a enunciados que dan cuenta de ciertos hechos, y los hechos no permiten por sí solos justificar una acción y decisión» ${ }^{17}$. Andrés Ollero, desde una mayor radicalidad, y con claras reminiscencias hermenéuticas, llega a afirmar: «actuar jurídicamente es siempre interpretar. Lo que se planteaba como un recurso de emergencia ante la obligada aplicación de la ley a "ca-

${ }^{15}$ Cit. por Larenz, K., op. cit., pág. 155.

${ }^{16}$ Warnock, G.J., «The Object of Morality», Londres, 1971, pág. 42.

${ }^{17}$ Nino, C. S., «Algunos modelos metodológicos de Ciencia Jurídica», Fontamara. México, 1993, págs. 21 y ss. 
sos difíciles", se desvela como la textura habitual de toda praxis jurídica. Poco a poco se va desvelando la secreta afinidad que convierte al jurista en oportuno aliado de una rehabilitación de la filosofía práctica. La actividad jurídica misma aparece como una peculiar respuesta en práctica de dicho filosofar... la actividad jurídica aparecerá ante todo como un juicio: como el enjuiciamiento de una conducta concreta a la luz de un principio valorativo... Lo judicial es un prius radical dentro de la diversidad de elementos que constituyen la realidad jurídica... Esa matriz judicial de lo jurídico lleva consigo una paralela prioridad de la justicia... no establecemos que el derecho debe ser justo, sino que constatamos que todo derecho es y se presenta como la búsqueda de un ajustamiento de las relaciones sociales. Sin ese intento -aparente, al menos- ninguna actividad sería recibida como realmente jurídica» ${ }^{18}$. En definitiva, la perspectiva operativa o interpretativa del derecho es una vía particularmente idónea para mostrar las insuficiencias y la ideología propia del paradigma dogmático-legalista, y por ende, privilegiando el momento final del ajustamiento, que implica el derecho, podemos elaborar una teoría realista que de cuenta de las razones explicatorias y justificatorias del derecho.

\section{El razonamiento jurídico como razonamiento práctico}

Ya la filosofía griega marcó como un clasificador «radical, primitivo y general» de todo saber y razonamiento el ser teórico o práctico, y luego de haberse reducido la razón -especialmente, a lo largo del siglo XIX, aunque ratificada y aplicada por el círculo de Viena- a la razón científico-demostrativa o a la razón lógico- matemática, en las últimas décadas se escucha, proveniente desde muy diversos sitios, el reclamo por «rehabilitar a la razón práctica», sin complejos cientificistas, centrada en dirigir, aconsejar o valorar el comportamiento humano. Finnis, en consonancia con el pensamiento clásico, recuerda que el saber teórico o especulativo se ocupa de lo que es, mientras que el saber práctico tiene por objeto lo que «ha de ser (is to be)», y en consecuencia, sus problemas típicos son ¿qué debe hacerse?, ¿qué no debe hacerse? y ¿qué debe omitirse?, aunque particularmente esta última pregunta es importante, ya que lo frecuente en el saber práctico o ético no es tanto elegir entre el bien o el mal sino el de saber cuál de los diversos bienes deben ser hechos o perseguidos ${ }^{19}$. El profesor de Oxford insiste en que la «razonabilidad práctica» es «razonabilidad en la decisión», en la adopción de compromisos, en la elección y ejecución de proyectos $\mathrm{y}$,

${ }^{18}$ Ollero Tassara, A., «¿Tiene razón el derecho?», Congreso de Diputados, Madrid, 1996, págs. 474 y ss.

${ }^{19}$ Finnis, J., «Natural Law and Natural Rights», Clarendon Press, Oxford, 1980, pág. 100. 
en general, en la acción. La filosofía práctica es una reflexión disciplinada y crítica sobre los bienes que deben ser realizados en la acción humana, y los requerimientos de razonabilidad práctica $»^{20}$. Kalinowski, desde iguales fuentes filosóficas, reitera que el saber práctico no se trata de saber qué es el bien en general, «sino, sobre todo, saber si el acto a realizar, aquí y ahora, es un bien o un mal», y la terminología clásica llama «prudencia» a esa capacidad de discernir en cada situación el bien y el mal concretos. El conocimiento jurídico no está abocado como el teórico o especulativo a contemplar esencias, sino que es práctico en tanto tiene por objeto dirigir el comportamiento humano y, así también «la interpretación jurídica es la interpretación práctica por excelencia... su fin no es la toma del sentido auténtico en vistas a su contemplación intelectual, sino la determinación de la regla de comportamiento», «aquél que interpreta un texto legislativo (en el amplio sentido) quiere llegar a saber en último lugar no solamente lo que el autor de ese texto ha dicho o ha querido decir (si es que esto puede saberse), sino cómo comportarse uno o cómo debe comportarse aquél que enseña (en el caso del profesor de derecho), o aconsejar (en el caso del abogado)» ${ }^{21}$.

Sabido es que ese reclamo por reconocer la practicidad del saber y del conocimiento práctico no sólo proviene de aquellos que se inspiran en la filosofía aristotélico-tomista, sino que se origina en orientaciones dispares. Así merece ser referenciado el esfuerzo de Alexy ${ }^{22}$ desde las perspectivas pragmáticas o éticas del diálogo para identificar al discurso jurídico como un caso especial del discurso práctico y, por ende, sometido a las 28 reglas del «código» de la razón práctica, muchas de ellas desbordando el plano meramente formal. O también la teoría de $\mathrm{Raz}^{23}$ basada en reconocer a las normas jurídicas como razones para actuar, pero postulando una completa filosofía práctica (una de sus ramas es la filosofía jurídica), con una parte sustantiva o valorativa (abocada a los argumentos construidos para mostrar qué valores debemos perseguir, qué razones para la acción deben guiar nuestra conducta, qué normas son vinculantes, etc.) y otra parte formal o de análisis conceptual (ocupada de las características lógicas, de conceptos tales como valor, razón para la acción o norma, y de la naturaleza de inferencia que gobierna el razonamiento práctico). En definitiva, al margen del respaldo de escuelas, nos importa consignar nuestra adscripción del razona-

${ }^{20}$ Ibídem, pág. 12.

${ }^{21}$ Kalinowski, G., «Philosophie et logique de l'interpretation du Droit», N. XVII, París, Sirey, 1972, págs. 41 y ss.

22 Cfr. Alexy, R., «Teoría de la argumentación jurídica», Ed. Centro de Estudios Constitucionales, Madrid, 1989.

${ }^{23}$ Cfr. Raz, J., «Practical Reason and Norm», Princeton University Press, 1990. 
miento jurídico a los razonamientos prácticos, y que, por ende, él es intrínsecamente axiológico, requiere de un método dialógico a los fines de alcanzar saberes que si bien parten de verdades universales, sólo proporcionan certezas probables a la hora de regular conductas humanas concretas ${ }^{24}$.

\section{El silogismo práctico judicial}

Haber afirmado la practicidad del razonamiento jurídico no implica sustraerlo a exigencias lógicas o formales. Es cierto que la lógica formal y la estructura silogística judicial terminaron con mala prensa después de la confianza excesiva que había despertado en los ámbitos del positivismo legalista. Entre las reacciones jurídicas más importantes en el continente europeo contra la lógica formal judicial ocupa un lugar destacadísimo Perelman y los diferentes expositores de las teorías sobre la argumentación, sin contar las reacciones radicales y absolutas que descalificaron a toda pretensión de racionalidad en el campo de las decisiones judiciales. Sin embargo, pensamos con Kalinowski ${ }^{25}$ que el razonamiento jurídico judicial se nutre de elementos para-lógicos o retóricos; de elementos extra-lógicos donde están dogmáticamente impuestas para el jurista presunciones, ficciones, etc.; pero, por supuesto, también requiere de elementos lógico-formales. Aun cuando los problemas lógico-formales no agoten los problemas del razonamiento judicial, lo cierto es que su consideración es forzosa, por lo que vale en aquél campo la conclusión genérica del ya citado Kalinowski: «todo razonamiento en tanto que es razonamiento depende de la lógica» ${ }^{26}$.

Admitir las exigencias lógico-formales sobre el razonamiento judicial implica vincular a éste con el silogismo deductivo, porque, como enseña Kalinowski, «el nombre de la lógica en su sentido más restringido designa a la lógica formal deductiva» ${ }^{27}$. Por ello, no sorprende la afirmación de Klug de que «la forma básica del razonamiento jurídico es el silogismo jurídico ${ }^{28}$, o de MacCormick, cuando reconoce en el derecho «un hogar seguro ${ }^{29}$ para la lógica deductiva. Más allá de los requerimientos lógico-deductivos que pesan sobre el razonamiento judicial. García Amado pone de relieve la

${ }^{24}$ Cfr. Massini, C. I., «La prudencia jurídica», Abeledo Perrot, Bs. As., 1983.

${ }^{25}$ Cfr. Kalinowski, G., «Introduction a la lógique juridique», Librairie Génerale de Droit et de Jurisprudence, París, 1965, cap. IV.

${ }^{26}$ Kalinowski, G. «Philosophie et logique de...», art. cit., pág. 48.

27 Kalinowski, G., «Introduction...», cit. pág. 42, y «La logique déductive», Presses Utuversitaires de France, 1996.

${ }^{28}$ Klug, V., «Lógica jurídica», Temis, Colombia, 1990.

${ }^{29}$ MacCormick, N., «The Nature of Legal Reasoning: A brief Reply to Dr. Wilson», Legal Studies, Nr. 2, 1982, pág. 290. 
«función retórica de legitimación de la decisión» ${ }^{30}$, que aquellos cumplen; e incluso Klug ${ }^{31}$ y Schreiber ${ }^{32}$ consideran que las leyes lógicas son normas de derecho no escritas, y exigidas por la Constitución. En definitiva, coincidimos con Alchourron y Bulygin, que «aunque sea verdad que para establecer las premisas del argumento uno debe recurrir a veces a interpretaciones, decisiones y valoraciones, el razonamiento, es decir, el paso que conduce de las premisas a la conclusión, es -o más bien, puede ser- reconstruido como una inferencia deductivas ${ }^{33}$.

Esta confianza y afirmación silogística respecto del razonamiento judicial supone recordar que el silogismo es una noción analógica, y que el silogismo de que hablamos los juristas es el práctico, en donde inevitablemente aparecen comportamientos, valoraciones y normas, amén de un marco institucional fuerte. Muchas de las críticas destinadas al silogismo judicial identifican a éste con las características propias del saber teórico, y en consecuencia, no alcanzan al silogismo práctico. Así, por ejemplo, Perelman, cuando denuncia las insuficiencias del silogismo, se basa en que «en el silogismo el paso de las premisas a la conclusión es necesario, no ocurre lo mismo cuando se trata de pasar de un argumento a una decisión» ${ }^{34}$; sin embargo, está incluido en el silogismo práctico esta exigencia decisoria (MacCormick) que no invalida la deducción aun cuando le ponga límites a aquélla. Victoria Iturralde ${ }^{35}$ también pone distancias con el silogismo judicial por su incapacidad para establecer las premisas; pero en realidad no es esa la pretensión silogística sino, simplemente, un control formal o estructural de la justificación interna; por eso, el razonamiento justificatorio no se agota en la dimensión deductiva. También Wellman ${ }^{36}$ le pide mucho, o improcedentemente, al silogismo, cuando lo plantea como una alternativa al reconocimiento de las inconsistencias en el derecho, pues la admisión de éstas no descarta per se la necesidad y conveniencia del control lógico deductivo sobre la decisión judicial. Tampoco nos parecen eficaces las dudas que introduce Atienza ${ }^{37}$, en torno a lógica formal deductiva, dado que la argu-

${ }^{30}$ García Amado, J. A., «Teorías de la Tópica Jurídica», Civitas, Madrid, 1988, pág. 196.

${ }^{31}$ Klug, V., op. cit., pág. 202.

${ }^{32}$ Schreiber, R., «Lógica del derecho», Sur, Bs. As., 1967, págs. 119 y ss.

33 Alchourron, C. - Bulygin, E., «Análisis lógico y Derecho», Ed. Centro de Estudios Constitucionales, Madrid, 1991, pág. 304.

${ }^{34}$ Perelman, C., «La lógica jurídica», op. cit., pág. 11.

${ }^{35}$ Iturralde, V., «Sobre el silogismo judicial», Anuario de Filosofía del Derecho, Madrid, 1991, págs. 239 y ss.

${ }^{36}$ Wellman, V. A., «Practical Reasoning and Judicial Justification: Toward an adequate Theory», University of Colorado Law Review, nr. 57, 1985.

${ }^{37}$ Atienza M., «Las razones...», cit. pág. 168. 
mentación jurídica se enfrenta con «argumentos a favor» $\mathrm{y}$ «en contra», y porque ella es «reticular» más que «lineal», en razón de que estas dudas se vinculan con lo externo de las premisas o ignoran el modo propio de la inferencia práctica. En definitiva, aun cuando reconozcamos que hay otros tipos de raciocinios que usa el juez al decidir, es necesario que él recurra a un silogismo deductivo o que se pueda reconstruir su iter con esa estructura «para pasar de lo general universal a lo individual (de lo abstracto a lo concreto)» ${ }^{38}$.

\section{Las premisas de los silogismos judiciales}

Hemos coincidido en el punto anterior acerca del recurso silogístico que hace el juez al razonar, y si bien es correcto afirmar que desde un punto de vista «macro» debe estar presente aquella estructura en la decisión, ello no implica sostener que sólo hay silogismos o que sólo hay un único silogismo. En efecto, amén de que el juez emplea raciocinios inductivos amplificantes, analógicos y estadísticos -según Kalinowski- nos interesa señalar que lo habitual es que haya «polisilogismos», o, como prefieren decir Aarnio ${ }^{39}$ y Peczenik ${ }^{40}$, hay «cadenas» o «árboles» silogísticos, pues recordemos además que el razonamiento judicial es normalmente entimático, en tanto hay ciertos argumentos que están implícitos u ocultos, y no explicitados o expresados.

Precisando lo señalado, estimamos que el juez básicamente estructura un «macrosilogismo», que contiene la decisión que resuelve el caso que lo ocupa y, por ende, debe establecer como mínimo la premisa mayor o enunciado normativo, la premisa menor o enunciado fáctico y la resolución o enunciado normativo individual. Pero además de estas tres inevitables decisiones ${ }^{41}$, hay una cuarta decisión, que en realidad es lógicamente primera en tanto posibilita o frustra las restantes; me refiero a lo que podríamos llamar «la decisión constitutiva de la litis». El objeto de ésta es precisar el problema que debe ser resuelto y si las partes han hecho lo que correspondía a los fines de que el juez efectivamente se pronuncie. Esta primera decisión se constituye en una especie de prerrequisito de las restantes, no sólo en cuanto fija las cuestiones acerca de las cuales se está discutiendo en el proceso, sino que además establece si la causa está en condiciones de obtener la res-

${ }^{38}$ Kalinowski, G., «Introduction...», cit., pág. 200.

${ }^{39}$ Aarnio, A., «Derecho, Racionalidad y Comunicación Social», Fontamara, México, 1995, pág. 58.

${ }^{40}$ Peczenik, A., «On Law and Reason», Dordrecht, 1989, págs. 126 y 158.

${ }^{41}$ Wroblewski menciona cinco decisiones: de validez, de interpretación, de evidencia, de integración o subsunción y final (Wroblewski, J., «Sentido y hecho en el derecho», op. cit., págs. 21 y ss.) 
puesta peticionada. Así, a manera de ejemplo, pensemos que puede ocurrir que lo reclamado por la actora no se encuentre perfilado con nitidez y que se requiera clarificar ese punto, $o$ también que la vía procesal adoptada o el sujeto que demandó o el órgano ante el cual se interpuso la demanda, no sean las que correspondieran. Esta decisión judicial inicial debemos suponer que también es fruto de un silogismo, pero de todas maneras en el presente trabajo no nos detendremos en ella, sino que prestaremos atención a las otras tres que ofrecen mayor interés teórico y práctico.

La segunda decisión, o sea, la premisa menor del macrosilogismo decisorio, tiene por objeto establecer un cierto enunciado fáctico, o sea, que ciertos hechos alegados por las partes y en base a la prueba aportada por las mismas, aquellos han sucedido en un espacio y tiempo determinados, y tienen una específica significación jurídica en orden a la litis planteada. Este momento decisional aparecía como irrelevante o sin complicaciones para el paradigma dogmático legalista, no obstante, que en él el juez contaba con una notable libertad y superior a la que disponía para la premisa mayor o normativa. Frank, entre otros, lo advierte cuando afirma que esa «discrecionalidad en cuanto a los hechos o soberanía virtualmente incontrolada o incontrolable, ha pasado por alto a la mayoría de los juristas ${ }^{42}$. Desde el «hecho bruto» (Larenz) hasta el hecho fijado y asignado en su proyección jurídica, un proceso en el que el juez no es propiamente un historiador -por utilizar el clásico símil de Calamandrei ${ }^{43}$ - porque se le exige imparcialidad, porque acepta ciertos hechos como dados aunque no haya prueba, porque excluye ciertas pruebas no obstante su capacidad probatoria y porque no es libre y tiene plazos para pronunciarse.

La tercera decisión o premisa mayor del silogismo medular judicial, es aquella en la que el juez establece una regulación jurídica general en la que puede subsumirse el hecho individual que debe resolver y disponer las respectivas consecuencias jurídicas. Este enunciado normativo excepcionalmente es una estricta repetición de una respuesta jurídica ya dada, especialmente ya dada por una ley, pues lo habitual es que el caso que se resuelve imponga alguna modalización o peculiaridad; pero aún en esa hipótesis extraña de reiteración más que de redundancia normativa, habría mantenimiento o confirmación de la vigencia de la regla en cuestión. Este reconocimiento de creación judicial se refleja en el valor y utilidad que tiene precisamente el «precedente» judicial, pues lo que estrictamente interesa a los operadores del derecho no es tanto la respuesta individual que se dio a un pág. 70.

${ }^{42}$ Frank, J., «Derecho e incertidumbre», Centro Editor de América Latina, Bs, As., 1968,

${ }^{43}$ Cfr. Asis Roig, R., «Jueces y normas», cit., pág. 127. 
caso sino la norma general en la que se subsumió el mismo, posibilitando dicha respuesta. Bulygin, sin perjuicio de poner en duda el carácter de jurídica de esa norma creada por los jueces, dada su falta de obligatoriedad y vigencia forzosa -por lo que les llama «anómalas»-, concluye: «jurídicas o no, éstas son las únicas normas que los jueces crean» ${ }^{44}$. Por nuestra parte, estimamos que esa norma general judicial una vez que adquirió el carácter de cosa juzgada y está justificada apropiadamente, ella es plenamente válida (existe jurídicamente y obliga -a su manera- a autores y destinatarios) y está vigente jurídicamente (es una respuesta jurídica disponible para los operadores y con razones para afirmar que será aplicada en los casos subsumibles); mientras que la validez se da o no se da, la vigencia admite grados de la misma. Más allá de estas diferencias, igualmente coincidimos con Alchourron y Bulygin que la premisa mayor es una norma y no una mera proposición normativa, lo que garantiza que la conclusión individual del silogismo sea normativa. Finalmente, pongamos de relieve que la creación normativa general judicial se expresa tanto negativamente (por ejemplo, cuando descarta interpretaciones positivas o normas válidas) como positivamente (por ejemplo, al explicitar normas implícitas, precisar definiciones, extender analógicamente respuestas vigentes, etc.)

La cuarta decisión es la conclusión que se infiere de las premisas puestas por el juez, y dado que estamos en el campo del saber práctico, importa destacar que puede haber más de una respuesta tolerada lógicamente por las mismas premisas, aun cuando quede igualmente determinado que algunas conclusiones son imposibles y otras necesarias. Si bien deberíamos llamar «sentencia» a la totalidad del razonamiento judicial resolutorio, esta conclusión es la que tiene el fallo en sentido estricto o la resolución al problema planteado en el proceso por las partes, y con él lo que en última instancia se establece, es la definición deóntica de ciertas conductas en cuanto prohibidas, obligatorias o permitidas, aunque Asis Roig entiende que el fallo puede ser o bien una norma definitoria o un imperativo específico. Jurídicamente esta norma individual es de importancia decisiva para las partes del proceso, pero carece de relevancia más allá del mismo, o mejor dicho, ello dependerá del aporte creativo que contenga respecto a lo ya establecido en las premisas. La validez y vigencia de esta norma judicial individual quizás resulten más indiscutibles, pues es evidente que ella existe jurídicamente o es válida en tanto esté justificada y obligando a sus destinatarios (partes procesales, auxiliares de la justicia, policía, etc.) y que además es vigente (hay fuertes razones para afirmar que será aplicada). Comparativa-

${ }^{44}$ Alchourron - Bulygin, «Análisis lógico y Derecho», cit., pág. 365. 
mente en relación a otras decisiones judiciales, la norma individual, es la que ofrece en principio menos discrecionalidad.

Hemos descrito las premisas del silogismo práctico que construye el juez de manera explícita o implícita a los fines de dar respuesta jurídica e imperativa a los problemas jurídicos que se van presentando en la sociedad, y puede haber quedado la sensación de que ese proceso cumplido por el juez es lineal y acumulativo. Sin embargo, ya advertimos sobre los raciocinios judiciales no silogísticos, sobre los silogismos con premisas no expresadas u ocultas y sobre los «polisilogismos» y ahora queremos prevenir acerca de que el contexto de descubrimiento judicial no siempre coincide con el contexto de justificación y, además, sobre la «recíproca compenetración entre los actos de constatación de hechos reales y los de calificación jurídica» (Schauerle) ${ }^{45}$. En efecto, Karl Engisch destacó con elocuencia acerca de ese «ir y venir de la mirada judicial» desde las normas a los hechos y desde los hechos a las normas («Hin- und Herwandern des Blicks») lo que constituye según Larenz «una manifestación del círculo hermenéutico» ${ }^{46}$. Es indudable que el juez, precisamente por el carácter práctico de su razonamiento decisorio, normalmente debe optar entre diversos silogismos que sólo puede apreciar apropiadamente si los tiene integralmente construidos a su disposición; en terminología clásica podríamos decir que la prudencia judicial antes de imperar o decidir tiene que conocer y juzgar entre diferentes alternativas que sólo puede apreciar si las representa no sólo en las conclusiones sino también con las premisas que las posibilitan.

\section{La justificación del razonamiento decisorio judicial}

En materia decisoria judicial entendemos por justificar o fundamentar a la exposición de los argumentos o las razones suficientes y apropiadas para establecer la validez jurídica de las decisiones judiciales ${ }^{47}$. Es cierto que hay autores que se han preocupado por distinguir entre justificación y fundamentación: el mismo Alexy $\mathrm{y}^{48}$ entiende que aquella es más amplia, pero sin embargo opta por usarlos indistintamente. Nosotros también los emplearemos como sinónimos aunque nos parece -con Ferrater Mora ${ }^{49}$ - que la fundamentación es más abarcativa, mientras que la justificación se vincula específicamente a las opciones dentro del saber práctico o ético. La exigencia de justificar supone la existencia de una duda, o la presencia de más de una

\footnotetext{
${ }^{45}$ Cit. por Larenz, K., «Metodología...», cit. pág. 275.

${ }^{46}$ Ibídem.
}

${ }^{47}$ Summers, R. S., «The Types of Substantive Reasons: The Core of a Theory of Common Law Justification», Cornell Law Review 63, 1978, págs. 724 y ss.

${ }^{48}$ Alexy, R., «Teoría de la argumentación jurídica», cit., pág. 52.

${ }^{49}$ Ferrater Mora, J., «Diccionario de Filosofía», Alianza, Madrid, 1990, pág. 1834. 
alternativa; por eso ya Aristóteles inscribía la deliberación racional en aquello «que está a nuestro alcance y es realizable», y la excluía respecto de las cosas eternas, de las cosas que siempre se suceden de la misma manera o del azar. Esta vinculación de la argumentación racional a la duda está presente en Cicerón: «rationem quac rie dubiae faciat fidem» y también en Alexy «de una justificación se hablará sobre todo cuando se ofrecen razones frente a una objeción o una duda» 50 .

En el terreno justificatorio judicial es inequívoco la presencia de un interlocutorio o destinatario del discurso, de quien se procura obtener el asentimiento, y esto ya está presente en la definición que trae Tomás de Aquino de argumento: «Argumentum dicitur, quod arguit mentem ad assen tiendum alicui» (se llama argumento lo que arguye la mente para convencer a alguien); por eso es oportuno recordar que metodológicamente el esfuerzo discursivo es dialógico o dialéctico (Villey) en tanto aparecen dudas, reclamamos agravios o argumentos a los que corresponde clarificar, responder o desechar o replicar. Siendo el argumento la expresión verbal o escrita del razonamiento, estamos presuponiendo la existencia del lenguaje, y, con él, la necesidad de respetar las reglas propias de su uso, y estar prevenidos acerca de los problemas que conlleva.

En esa exposición argumental no sólo pesan las exigencias lingüísticas, sino también las estrictamente lógicas o formales, y las que avanzan en lo sustancial o contenido de los argumentos. En este punto nos parece conveniente estar advertidos de las insuficiencias de las justificaciones meramente formales, y además de las insuficiencias de las justificaciones exclusivamente jurídicas autoritativas. En efecto, los riesgos de circularidad, arbitrariedad o dogmatismos de los juridicismos justificatorios han sido señalados clásicamente por los iusnaturalismos que reclaman una razón jurídica abierta a los bienes o valores humanos básicos (Finnis), pero contemporáneamente autores como Nino reclaman que la justificación jurídica culmine en la moral y en la objetividad: «La justificación que recurre a una norma jurídica que se supone válida, debe depender en última instancia para fundamentar esa validez de: a) normas que sean b) categóricamente aceptadas, c) por su contenido y que d) pretendan tomar en cuenta imparcialmente los intereses de todos los afectados. Vale decir, normas morales» ${ }^{51}$.

A criterio de $\mathrm{Raz}^{52}$, una de las tres características más generales e importantes del derecho es el ser institucionalizado, y Alexy considera que los

${ }^{50}$ Alexy, R., «Teoría de la argumentación jurídica», cit.

${ }^{51}$ Nino, C. S., «Respuesta a J. J. Moreno, P. E. Navarro y M. C. Redondo», en Doxa, nr. 13, 1993, pág. 262.

${ }^{52}$ Raz, J., «The Concept of a Legal System. An Introduction to the Theory of Legal System», Clarendon Press, Oxford, 1980; Atienza, M. «Las razones del Derecho». cit., pág. 39. 
enunciados doctrinarios (él los llama «dogmáticos») se forman, fundamentan y comprueban «en el marco de una ciencia del derecho que funciona institucionalmente $»^{53}$. Creemos que el discurso justificatorio judicial no sólo se cumple en ese marco institucionalizado del derecho, sino que él es prueba inequívoca de esa dimensión institucional, pues, además de competencias, procedimientos, órganos, jerarquías, etc., están presentes en aquél normas, convenciones, recomendaciones, etc.

Finalmente, y antes de introducimos en las funciones que cumple la justificación, aludamos a una distinción que, introducida por Wroblewski ${ }^{54}$, logró importante aceptación; nos referimos a la clasificación entre justificación interna y justificación externa: mientras aquella remite a las vinculaciones lógicas o formales una vez puestas las premisas, la otra se ocupa de la justificación de las premisas mismas. Esta distinción tiene la utilidad de llamar la atención sobre las insuficiencias de la lógica, y la importancia del discurso axiológico y del oculto, y que en consecuencia, un control integral sobre el discurso justificatorio no puede perder de vista esas dimensiones. Sin embargo, tiene el riesgo de desconocer que es muy difícil y de dudosa conveniencia señalar en la práctica cuándo termina la justificación interna y empieza la externa, amén de ignorar que el juez opta entre discursos justificatorios completos y no fraccionados.

\section{Funciones de la argumentación justificatoria}

La historia del Derecho no es muy favorable hacia la imposición al juez de justificar sus decisiones. En Francia, a finales del siglo XIII, se abandona por los jueces la práctica de motivar, incluso se llega a advertir a los jueces que deben cuidarse de mencionar la causa de la decisión y, además, estaba prohibido publicar las resoluciones judiciales sin autorización del parlamento. Montesquieu, en el siglo XVIII, manifestaba la inconveniencia de justificar las sentencias, dado que con ello se promovían entorpecimientos por parte de quien perdía el juicio. Será después de la Revolución Francesa -concretamente, en 1790cuando se dictan normas que establecen la obligatoriedad de la motivación de las sentencias civiles y penales.

Prieto Sanchís ${ }^{55}$ asocia al absolutismo la falta de interés para la motivación de las decisiones judiciales; y diversos autores insisten en remitir la

${ }^{53}$ Alexy, R., «Teoría de la argumentación jurídica», cit., pág. 245.

${ }^{54}$ Wroblewski, J., «Legal Syllogism and Rationality of Judicial Decision», en Rechtstheorie 5 (1974), págs. 39 y ss.; Redondo, M. C., «La noción de razón para la acción en el análisis jurídico», Ed. Centro de Estudios Constitucionales, Madrid, 1996, págs. 217 y ss.

${ }^{55}$ Prieto Sanchís, L., «Ideología e interpretación jurídica» Tecnos, Madrid, 1987, pág. 116. 
exigencia de fundamentación al proceso de democratización. Lo cierto es que constatamos en nuestro tiempo lo que escribe Aarnio: «la responsabilidad del juez se ha convertido cada vez más en la responsabilidad de justificar sus decisiones ${ }^{56}$, de modo que el primer reclamo al decisor es más que decidir de un cierto modo, es decidir exponiendo razones o argumentos. Más allá de esa comprobación «empírica», es legítimo preguntarse el por qué de esta necesidad de justificación, y así pueden esbozarse «respuestas metafísicas», que descansen en la naturaleza humana y en sus inclinaciones y primeros principios de la razón; «respuestas culturales», que la vinculen a un cierto tipo cultural o «forma de vida», sin que exista nada necesario en ello; «respuestas utilitaristas o técnicas», que pongan el acento en las ventajas de adoptarlas por los fines que procuran; «respuestas definitorias $o$ voluntaristas», en tanto lo remiten al establecimiento por acuerdo o por una autoridad; etc.

Las funciones que cumple la argumentación justificatoria son variadas y, entre ellas, nos parecen destacables:

1) función validante: $\operatorname{Cotta}^{57}$, a partir de entender que una norma es un plexo compuesto por enunciado deóntico, justificación e interpretación, ha concluido que «la obligatoriedad de la norma depende de la validez de su justificación, que es, por consiguiente, el fundamento de aquélla», y en consecuencia la validez de una norma depende de su justificación;

2) función controladora: atento a que la sentencia es una unidad, sólo puedo juzgarla considerando las razones que intentan avalarla, y, además, el carácter institucional ya apuntado se manifiesta en los distintos tipos de $\operatorname{control}^{58}$ : el académico, el superior, el profesional, el social, el político, el disciplinario, etc.,

3) función legitimadora: Mauro Cappeletti ${ }^{59}$ entiende que los jueces se legitiman en el ejercicio de su poder a través de la práctica de ciertas «virtudes pasivas, formales o procedimentales», entre las que destaca la justificación de las decisiones;

4) función concretizadora: aquella orden racional general que implica la ley reclama intrínsecamente ser proyectada a los casos que en ella se subsuman, de modo que esa obra humana racional se acaba o completa en la tarea individualizadora judicial;

${ }^{56}$ Aarnio, A., «Lo racional como razonable», cit., pág. 29.

${ }^{57}$ Cotta, S., «Justificación y obligatoriedad de las normas», CEURA, Madrid, 1987, pág. 23.

${ }^{58}$ Tarello, G., «L’interpretazione della legge», Milano, Giuffrè, 1980, págs. 67 y ss.

${ }^{59}$ Cappeletti, M., «Giudici legislatori?», cit., págs. 63 y ss. 
5) función didáctica: las reglas jurídicas intentan ser modelos y causas eficientes de conductas; por eso la explicación y proyección operativa a sus destinatarios favorece el conocimiento de las mismas y su eficacia;

6) función científica: a la hora de la descripción y reconstrucción sistemática del derecho vigente, con su modo de operatividad, sus fuentes del derecho, etc., es forzoso atender al discurso justificatorio judicial;

7) función estabilizadora: justificando la proyección de las respuestas jurídicas generales a los casos, es posible descargar futuras argumentaciones mediante la invocación de esos precedentes y aportar a la previsibilidad de respuestas concretas;

8) función pacificadora: la argumentación apropiada cumple una función persuasiva y no meramente resignada respecto de aquellos a los que son derrotados en el proceso;

9) función moralizadora: al inscribir la autoridad en el ámbito de lo racional, y así superar el conflicto moral -apuntado por Kant- que supone el disponer acerca de la libertad del otro.

\section{Cuadro sinóptico de los argumentos o razones justificatorias judiciales}

Las limitaciones impuestas en tomo a la extensión de este trabajo exigen que nos limitemos a indicar a continuación -y de manera muy esquemática y sucinta- las razones o argumentos idóneos para lograr la justificación de las diferentes decisiones judiciales: 